\title{
LA VACA SOBREINTERPRETADA (ACERCA DE LA CONSTRUCCION DE IDENTIDADES COLECTIVAS)
}

José Vilas Nogueira *

Hace alrededor de tres años, Jon Juaristi publicó El bucle melancólico, un libro de "historias de nacionalistas vascos". Hace algo menos tiempo lo he leído yo. No me voy a referir al conjunto del libro, sino a uno de sus capítulos iniciales. Dos están consagrados a Unamuno. El segundo de ellos se titula "El bardo de Hendaya" y es, sustancialmente, el análisis de un poema de don Miguel.

Juaristi hace una "sobreinterpretación" -así lo dice él mismo-del poema. No voy a discutir la legitimidad de este procedimiento en los terrenos de la filología o de la crítica literaria. Pero sí diré que es un recurso siempre peligroso, y potencialmente catastrófico, aplicado al análisis de discursos, figuras o movimientos políticos. Y, además, la sobreinterpretación que hace Juaristi es manifiestamente inconsistente.

El autor hace una generosa utilización del anagrama como recurso interpretativo, incluyendo lo que él llama "semianagrama" (por ejemplo "el caso del semianagrama hojas-hijos [H-J-S]", en la página 117; "olas es semianagrama de hojas $[O-A]$ ", en la página 120 ; etc.). Dado que hay otros posibles "semianagramas" de cualquiera de estas palabras, por ejemplo herejes; por ejemplo, ocas (naturalmente, hay algunos más); dado que como la h de hojas-hijos es muda (precisamente a la opinión que Unamuno tenía sobre la utilidad de las haches mudas en vascuence hace repetida referencia Juaristi) es bastante dudoso que sea pertinente su utilización en la atribución de significatividad a un semianagrama (¿o estamos simplemente a hacer crucigramas? Dado todo esto, uno se puede preguntar si este recurso no sobrepasa los límites de la argumentación razonable. Estas libertades interpretativas, en un autor que exhibe una gran cultura filológica y literaria, paradójicamente, disminuyen la plausibilidad de su discurso, prestándole apariencia de práctica de prestidigitador.

*Catedrático de Ciencia Política. Universidad de Santiago de Compostela. 
El poema de Unamuno es una especie de elegía por unos muertos vascofranceses en la Primera Guerra Mundial, sugerida por la contemplación de una lápida funeraria en una pequeña iglesia de aquella región. La conclusión de Juaristi es que este poema refleja la comprensión unamuniana del País Vasco como matria intrahistórica. Su crítica pretende resituar al pueblo vasco en la historia. La conclusión es certera; lo sorprendente es el alarde de erudición que despliega para llegar a tal término, sino obvio, no muy inesperado. Sin duda, tiene razón Juaristi al reivindicar las razones de la historia, pero éstas se pueden justificar aceptablemente sin necesidad de sobreinterpretaciones.

Lo llamativo, para mí, del caso de Juaristi, que fue nacionalista y ya no lo es, es su gusto por permanecer en el universo ideológico nacionalista, aunque sea para negar la nación vasca y el consiguiente nacionalismo. Es llamativo para mí, pero no lo debe ser para todo el mundo, pues, por ejemplo, en Galicia, hay escritores que tampoco son nacionalistas, que hacen más o menos lo mismo. Consagrarse a estudiar naciones que uno cree que no existen es una empresa formidable.

Ciertamente, en todas las naciones suelen existir nacionalistas. Pero ninguna nación se compone sólo de nacionalistas. Normalmente la relación es inversa, cuanto más nación, menos nacionalistas. Pero este es terreno resbaladizo y subjetivo, y no es mi intención provocar a los nacionalistas, vascos o de otro lado. Tampoco pretendo discutir de Unamuno, del que sé muy poco, ni cuestionar la conclusión de Juaristi. Lo que me interesan son algunos de los argumentos que emplea este último, en particular su recurso a la vaca como tema ilustrativo del vasquismo intrahistórico de don Miguel (páginas 124 a 130, nada menos).

Caramba, ¿seremos los gallegos, vascos también? Y aunque en España parece que casi todos quieren ser lo que no son, yo prefiero ser lo que soy. Este conformismo tiene muchas ventajas: no sólo es cómodo (como todo conformismo); también es menos propenso al ridículo; también es más democrático; de la democracia de verdad, que no consiste en inventarse una fantasmal hipóstasis, para en su nombre legitimar gustos muy particulares y más o menos escogidos, no compartidos por la gente "realmente existente". La democracia verdadera es aceptar que la gente común puede tener gustos diversos de los de las elites. Una cosa bien maravillosa es el complejo de inferioridad de las elites nacionalistas gallegas respecto de los catalanes y de los vascos. Ruin debe de ser su nación si tienen que procurarse modelos fuera. Ruin ha ser su patriotismo si implican constantemente, y explicitan a veces, que la mayoría de la gente común está alienada y es desleal y estúpida. Los nacionalismos radicales no sólo son peligrosos para la paz civil; son inconsistentes lógicamente, pues hablan en nombre de un pueblo que, "alienado", quiere cosas distintas de las que quieren sus oficiosos portavoces.

Unamuno pensaba que la vaca era el animal totémico de los vascos. Pero éste es un totem muy inespecífico. De vacas estaba poblado el horizonte vital de mis ascendientes, apenas lejanos en una o dos generaciones, y cada día más próximos, a medida que el paso de los años me va acercando al final del trayecto. La vaca es 
el motivo de la célebre viñeta de Castelao ilustrativa de la "explotación" de Galicia por Madrid (tenía la cuadra en Galicia y la ubre en Madrid). La vaca es el motivo de otra célebre estampa de Castelao ilustrativa de la "explotación" interior a Galicia ("decías que eras pobre, y tenías una vaca"). La vaca es el motivo de una crítica literaria de Castelao de las familias señoritingas y melindrosas de la ciudad ("lloran la muerte de un perrillo faldero y se ríen del llanto de una familia campesina a la que le murió la vaca"; las citas son de memoria; no pretenden ser exactas). En nuestra literatura hay mil ejemplos más. Aún hoy, la vaca protagoniza en Galicia con frecuencia importantes movilizaciones sociales e importantes discusiones políticas.

Naturalmente, Juaristi no es tonto y en su extenso tratamiento de la vaca como tema del vasquismo intrahistórico de Unamuno no sólo no afirma una especificidad vasca sobre la vaca, sino que hace abundantes referencias, unas mejor, y otras peor traídas, a autores no vascos que también se refieren a la vaca. Pero, estas referencias y otras similares sobre otros temas del vasquismo intrahistórico unamuniano hacen su discurso gratuito pues implican que no hay particularidad. Al cabo, como en el caso del nacionalismo, de muchos nacionalismos, es una discusión sobre "particularidades", que sólo son tales en la imaginación y la intención de los que las postulan.

Documentaré esta afirmación, aunque exija un algo tedioso seguimiento del texto de Juaristi. La vaca, dice él, es un elemento indispensable de la "pastoral pirenaica". Ilustra esta singular afirmación de un modo asombroso, verdadero ejemplo de sobreinterpretación. Porque, haciendo uso de su envidiable cultura literaria, recurre a Juan Ramón Jiménez, que, sin duda, todos reconoceremos como esclarecido cultivador de la "pastoral pirenaica" ( $i$ ). Efectivamente, Juan Ramón estuvo internado en un sanatorio del Pirineo, no sé si aragonés o catalán, y escribió una "pastoral", que transcribe Juaristi. En su pastoral había vacas con la misma naturalidad que había vacas en los Pirineos. Si el poeta de Palos de Moguer se hubiese conformado con aires menos oxigenados, y en Galicia la industria médica hubiese estado más desarrollada, podría haber venido a Galicia y habría escrito la misma pastoral (salvo la última estrofa, por cierto despreciable poéticamente e inconsistente argumentalmente, que aquí no encajaba en modo alguno; el lector interesado puede verla en la página 125 del libro de Juaristi). Tendríamos, entonces, un ejemplo de "pastoral nordatlántica". Si Juan Ramón hubiese estado tan fuerte como un roble (no necesariamente de Guernica; Unamuno y Juaristi parecen implicar que el roble "esencial" es el de Guernica; los otros robles son meros epifenómenos) y hubiese ido de descanso a algún campo de Segovia, seguro que en su pastoral no habría vacas; habría ovejas.

Estas cosas son tan evidentes que no precisan de muchas interpretaciones, y excluyen sobreinterpretaciones. Juaristi cree que Unamuno conocía el poema de Juan Ramón y que, por tanto, fue influido por él. Esto es perfectamente plausible, sobre todo porque las vacas de Juan Ramón, como las de Unamuno, llevaban cencerros. Pero, manda narices, con perdón, resulta que las vacas de Biriatu, que 
es el lugar vascofrancés que está en la génesis del poema de Unamuno, no llevaban -como la generalidad de las nuestras tampoco llevan - cencerro. Claro, el problema no es de pastorales pirenaicas o nordatlánticas, juanramonianas, unamunianas, o de cualquier otro tipo, inventado o por inventar. Tampoco requiere sobreinterpretaciones. En las montañas de los Pirineos las vacas "deben" llevar cencerros, para facilitar su búsqueda si se pierden. En las explotaciones familiares del valle vascofrancés de Labort, donde se encuentra Biriatu, o en nuestros valles, los cencerros de las vacas sólo sirven para impresionar a los vecinos, que no siempre agradecen el gesto. Es mejor, no ponérselos.

Entregado a la confortable sobreinterpretación, Juaristi dice de la vaca que es el animal totémico de los campesinos vascos, convive con ellos, y a veces ocupan un mismo espacio en el caserío. Pues, justamente, lo mismo que aquí, lo mismo que en otras muchas culturas campesinas de Europa occidental (y, por supuesto, también de algunas otras regiones). Una vez fui a un museo rural en las Landas. Es sabido que los franceses son maestros en la "substanciación museística". Algo que en otro lado puede resultar enteramente trivial, para un francés es siempre potencial objeto de museo. En esos inefables museos locales franceses usted puede encontrar los calzoncillos de M. le Curé o de M. le Maire (exagero un poco, pero no sin envidia; me gustaría que entre nosotros se diese algo semejante). Bueno, pues en ese museo etnográfico de las Landas, todo era muy parecido a lo que yo aún recuerdo de nuestras aldeas, a pesar de las muy obvias e importantes diferencias del hábitat respectivo.

Un campesino de la unamuniana Paz en la guerra, acariciaba con la mirada su vaca porque le daba becerros, leche y estiércol (la cita no es literal). Pues, claro, como aquí. Ya evoqué antes la expresión de Castelao a propósito de la relación económica y afectiva (en el mundo de los "progres" una y otra relación suelen ser antitéticas; en el mundo real casi siempre van de consuno) de las familias campesinas con las vacas. Las relaciones de producción, en la extensión más amplia -y no necesariamente impropia-de la palabra implican relaciones específicas con el entorno natural, y por tanto con los animales, y más específicamente con los animales integrados en los procesos de producción, principalmente los animales domésticos. Vincular esta especie de relaciones a experiencias "nacionales", "protonacionales" o "paranacionales" (por referencia a cualquier nación o "nación") es una miseria introducida por el pensamiento nacionalista. Las vacas son tan totémicas en el País Vasco como pueden serlo en Galicia, en Asturias, en Cantabria, y en otros muchos sitios del mundo.

En muchos sitios del mundo, pero, claro, no en todos. Juaristi evoca otro personaje de Paz en la guerra, a quien una campesina de "ojos bovinos" despierta un turbador complejo de deseo y vergüenza. Y, una vez más, aplica su gran cultura literaria al estéril juego que se trae entre manos: “'La de los ojos de vaca' es el epíteto que se aplica en la Ilíada a Hera, la madre de los dioses. La de la vaca es, en consecuencia, imagen materna investida de sacralidad, epifanía o avatar de la diosa madre” (pág. 126). 
No parece muy serio, ¿verdad?. Aunque, infelizmente, mi conocimiento de la cultura griega clásica sea muy limitado, no parece muy aventurado entender que hay, por lo menos, dos modos de tratar la Ilíada. Uno, como registro de la sociedad que realmente existió en la Grecia de, más o menos, el siglo VIII a.C., donde no es sorprendente que la vaca tuviese un papel importante y, por tanto, el aspecto de sus ojos fuese prestado a, nada menos, que la madre de los dioses. Otro, "cargado" con todas las interpretaciones y "sobreinterpretaciones" posteriores, cuya evocación parece impertinente para el objetivo de explicar una sociedad real o presuntamente ahistórica, que, por definición de los "definidores", da la espalda a cualquier referencia al "milagro griego", por utilizar la socorrida expresión. Y, en conexión con esta segunda manera, aun hay un tercer modo posible, que es explotar la Grecia clásica y sus mitos en vena psicoanalítica como "sacral imagen materna, epifanía o avatar de la diosa madre".

A partir de aquí, el tratamiento de Juaristi se degrada manifiestamente. Primero, con una referencia a un poema de Joan Maragall dedicado a una "vaca ciega" (tema poético realmente meritorio, por singular), que no tiene nada qué ver con su argumento. Después, con una referencia a Isaac B. Singer, "ante el escaparate de una carnicería de Varsovia", que aun tiene menos qué ver, y que tomada en serio sugeriría una revisión de la Ilíada, en cuanto a la necesidad de dotar de unos nuevos ojos a Hera. En tercer lugar, con la asombrosa "sobreinterpretación" de que lo que interesa a Unamuno de la "vaca de Maragall" es "su ausencia de pensamiento reflexivo, de conciencia: lo que la emparenta con los primitivos, con los hombres de la intrahistoria, con los campesinos vascos" (pp. 127-128).

En pocas palabras, Juaristi viene a decir que Unamuno pensaba que los campesinos vascos eran como vacas, no por los ojos, porque tuviesen cuernos o porque diesen leche, o por cualquier otro atributo o circunstancia más o menos típicamente vacuno. No, Unamuno pensaba que los campesinos vascos eran como vacas porque no tenían conciencia. Como esta ausencia no es nada específica de las vacas, con esta maravillosa sobreinterpretación se podría sostener igualmente que los campesinos vascos eran como hormigas, como anchoas, como zorros, etc. (ninguno de estos animales, que se sepa, tienen conciencia). Con gran ingenuidad, Juaristi cuenta que Paul Valéry correspondió al envío de uno de los poemas de Unamuno - "Miraba a la mar la vaca"-, diciendo sentirse vaca. Seguramente, Unamuno que, en tanto poeta, en aquella altura de su vida, era tan presuntuoso como mediocre -su poesía no merece consideración hasta mucho más tarde y no precisamente en poesías de tema "vasco"—no entendió la desdeñosa ironía del francés. Si Valéry hubiese conocido la sobreinterpretación juaristiana podría interpretarse su expresión como una muestra de "finesse d'esprit", para decir que se sintiera como un "campesino vasco". Pero esto evidentemente es imposible, y Juaristi no parece a este propósito más agudo que Unamuno.

Terminamos con la vaca. Les diré sólo que la sobreinterpretación abunda en temas tan específicamente vascos, como el roble; las hojas arrebatadas por el 
viento; el pedrisco (que para Unamuno puede ser intempestivo; si hubiese sido agricultor es difícil que encontrase un pedrisco "tempestivo"; y que para Juaristi es sólo un anagrama), el manriqueño, de las vidas, que como los ríos, se pierden en la mar; la ambigüedad de la sepultura/seno materno (puestos en estas, Juaristi podría haber recurrido a Freud); el cañón y la tierra (masculino y femenino; misma ausencia); los corderos; los pacifistas; las madres de los soldados que van a la guerra; qué no sabemos porqué nacimos ni para qué; el arar en el campo y el campo arado (a los que Juaristi, no se sabe por qué, ya no atribuye significado sexual; ¿cuál es la diferencia con el cañón y la tierra, o la lluvia y la tierra?).

Como se ve, todo muy pertinente y muy específico para entender el vasquismo intrahistórico de Unamuno. Si yo fuese una autoridad les excitaría a practicar la sobreinterpretación. El campo es ilimitado y los rendimientos inagotables. Como infelizmente no soy una autoridad me consuelo con los últimos versos (tampoco demasiado buenos) del poema de Unamuno, que comenta Juaristi, "los ríos a la mar ... es la costumbrely con ella pasamos". 